\title{
EXPERIMENTAL ROTORDYNAMIC COEFFICIENT RESULTS FOR TEETH-ON-ROTOR \\ AND TEETH-ON-STATOR LABYRINTH GAS SEALS ${ }^{1}$ \\ Dara W. Chtlds and Joseph K. Scharrer \\ Texas A\&M University \\ College Station, Texas, 77843
}

An experimental test facility is used to measure the rotordynamic coefficients of teeth-on-rotor and teeth-on-stator labyrinth gas seals. Direct damping coefficients are presented for these seals for the first time. The results are presented for the two seal configurations at identical operating conditions, and show that, in a rotordynamic sense, the teeth-on-stator seal is more stable than the teeth-on-rotor seal, for inlet tangential velocity in the direction of rotation.

\section{NOMENCLATURE}

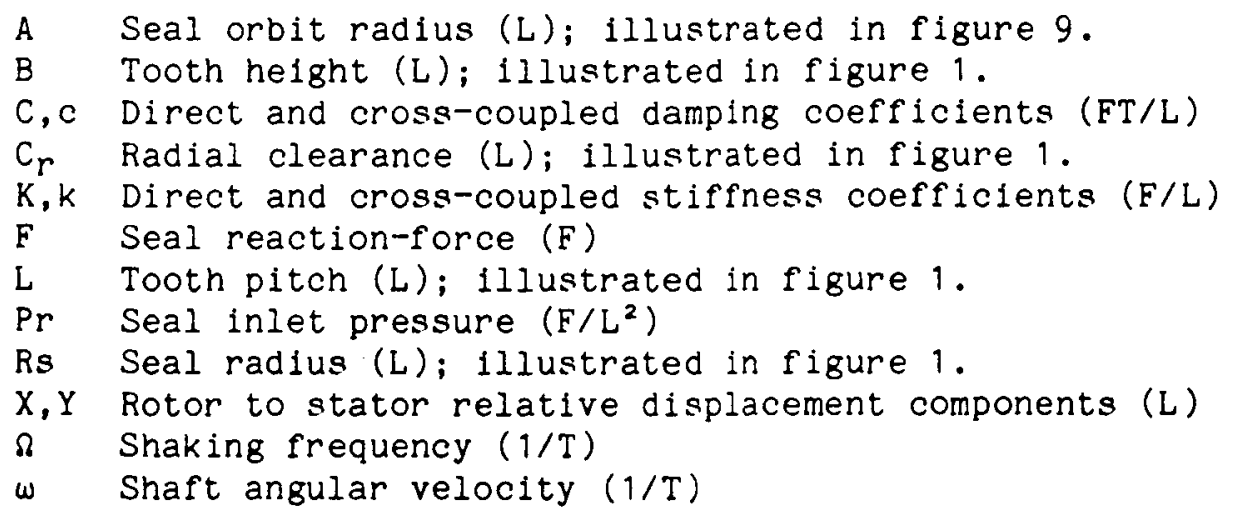

$\begin{array}{lll} & & \text { Subscripts } \\ r & \text { Value in } 1-t h \text { cavity } \\ t & \text { Tangential component } \\ x, y & \text { Rectangular coordinate directions }\end{array}$

1 This work was supported in part by NASA Grant NAS3-181 from NASA Lewis Research Center (Technical Monitor, Robert Hendricks) and AFOSR Contract F49620-82-K-0033 (Technical Monitor, Tony Amos). 


\section{INTRODUCTION}

The design, development, and operation of the test apparatus and facility which have been developed to measure the leakage and rotordynamic coefficients of annular gas seals has been described by Childs et al. [1]. This apparatus has been designed and used to measure rotordynamic coefficients of plain annular seals, plain seals with honeycomb stators, and labyrinth seals. Nelson et al. [2] presented the results for plain annular seals with constantclearance and convergent-tapered geometries. This paper presents the results for "see-through" labyrinth seals, as shown in figure 1, with teeth on the rotor and teeth on the stator.

As described in [1], the rotordynamic coefficients for a gas seal are defined by the following linearized force-displacement model.

$$
-\left\{\begin{array}{c}
F_{x} \\
F_{y}
\end{array}\right\}=\left[\begin{array}{ll}
K_{x x} & K_{x y} \\
K_{y x} & K_{y y}
\end{array}\right]\left|\begin{array}{l}
X \\
Y
\end{array}\right|+\left[\begin{array}{ll}
C_{x x} & C_{x y} \\
C_{y x} & C_{y y}
\end{array}\right]\left|\begin{array}{l}
\dot{X} \\
\dot{Y}
\end{array}\right|
$$

Where $(X, Y)$ define the motion of the seal's rotor relative to its stator, $\left(F_{x}, F_{y}\right)$ are the components of the reaction force acting on the rotor, and $\left(K_{x x}, K_{y y}, K_{x y}, K_{y x}\right)$ and $\left(C_{x x}, C_{y y}, C_{x y}, C_{y x}\right)$ are the stiffness and damping coefficients respectively. Equation (1) applies for small motion of the rotor about an arbitrary eccentric position. For small motion about a centered position, the following simpler model applies.

$$
\left.-\left\{\begin{array}{l}
F_{X} \\
F_{y}
\end{array}\right\}=\left[\begin{array}{cc}
K & k \\
-k & k
\end{array}\right]\left\{\begin{array}{l}
X \\
y
\end{array}\right\}+\left[\begin{array}{cc}
c & c \\
-c & c
\end{array}\right] \mid \begin{array}{l}
\dot{X} \\
\dot{y}
\end{array}\right\}
$$

Although the test apparatus has the capability of separately identifying the eccentric-position rotordynamic coefficients of equation (1), the results presented here are for the centered-position case only.

A limited amount of experimental data have been published to date on the determination of the stiffness coefficients for labyrinth gas seals. However, no data have been published concerning the damping coefficients of labyrinth gas seals. The first published results for stiffness coefficients were those of Wachter and Benckert $[3,4,5]$. They investigated the following three types of seals: a) teeth-on-stator, b) interlocking teeth on the rotor and stator, and $c$ ) teeth on the stator and steps or grooves on the rotor. Seals were tested in the following two modes: a) No seal rotation, but fluid prerotation, and b) seal rotation but zero fluid prerotation. These results were limited in that the pressure drop was small, much of the data was for nonrotating seals, no data were presented for teeth-on-rotor seals. The next investigation was carried out by Wright [6], whose results were for single-cavity teeth-on-stator seals with convergent, divergent, or straight geometries. Although this was a very limited and special case, these results did give insight into the effects of pressure drop, convergence or divergence of the clearance, and forward or backward whirl of a seal. The most recent investigation was that of Brown and Leong [7], who investigated various teeth-on-stator seal configurations. Their results include variations of pressure, geometry, rotor speed, and inlet tangential velocity. 
In reviewing previous experimental programs, there is a clear need for extensive testing of seals with teeth on the rotor and results for measured damping coefficients. This paper present some initial results for stiffness and damping coefficlents for two, nominally-identical seals, differing only in that one is a tooth-on-rotor configuration and the other is a tooth-on-stator configuration. The test apparatus, facilities, and data-identification procedures used in this study are described in detall in references [1] and [2].

\section{EXPERIMENTAL RESULTS}

The rotor and results for measured damping coefficients. This paper present some initial results for stiffness and damping coefficlents for two, nominally-identical seals, differing only in that one is a tooth-on-rotor configuration and the other is a tooth-on-stator configuration. The test apparatus, facilities, and data-identification procedures used in this study are described in detail in references [1] and [2].

The test results reported here were developed as a part of an extended, joint NASA-USAF funded research program for annular gas seal studies. Tests were of a smooth-rotor/labyrinth-stator seal and a labyrinth-rotor/smoothstator seal. The test program had the initial objective of comparing the leakage and stability performance of a teeth-on-stator and a teeth-on-rotor labyrinth seal. Air is the test fluid.

Test Apparatus and Seal Configuration

The rotor shaft is suspended pendulum-fashion from an upper, rigidly mounted pivot shaft, as shown in supported in the test section housing by three configuration. Different seal stator designs are obtained by the use of inserts.

The dimensions and pertinent data for each seal configuration are given in table 1. The constants given in table 1 for Fanning friction factor determination ( $\mathrm{mr}, \mathrm{nr}, \mathrm{ms}, \mathrm{ns}$ ) are the same as those determined for the constantclearance seal case as discussed by Nelson et al. [2]. The smooth and labyrinth stator inserts used for these tests are shown in figure 4 . The labyrinth rotor and the tooth detail for both rotor and stator are shown in figures 5 and 6 .

Table 1. Dimensions and parameters of seals tested in this study

Teeth on rotor

Radius $(\mathrm{cm})$
Length $(\mathrm{cm})$
Tooth pitch $(\mathrm{cm})$
Tooth height $(\mathrm{cm})$
Clearance $(\mathrm{cm})$
$\mathrm{mr}$
$\mathrm{nr}$
$\mathrm{ms}$
$\mathrm{ns}$

Avg. Inlet Temp. (K)

$$
\begin{aligned}
& 7.25 \\
& 5.08 \\
& 0.3175 \\
& 0.3175 \\
& 0.0406 \\
& -0.33 \\
& 0.187 \\
& -0.33 \\
& 0.187
\end{aligned}
$$

300.0
Teeth on stator

$$
\begin{aligned}
& 7.56 \\
& 5.08 \\
& 0.3175 \\
& 0.3175 \\
& 0.0406 \\
& -0.33 \\
& 0.187 \\
& -0.33 \\
& 0.187 \\
& 300.0
\end{aligned}
$$


Test Variables

When shaking about the centered position, the Dynamic-Seal-Apparatus is capable of controlling the following three independent variables: pressure ratio, rotor speed and inlet tangential velocity. The actual test points for each of these three independent variables are shown in table 2. When reviewing the following figures, table 2 should be consulted for the definitions of all symbols used.

The pressure ratios achieved at the TAMU facility were up to 2.5 times larger than those published by wachter and Benckert $[3,4,5]$. The reservoir pressures, as measured upstream of the flowmeter, are given in table 2. These values differ from the actual inlet pressure, as given in the pressure distribution plots, because of frictional losses and an acceleration of the fluid due to the inlet guide vanes. No tests could be run at zero pressure difference, since a small pressure difference is necessary to keep the rotor from shifting axially and rubbing the inlet guide vanes.

Table 2. Definition of symbols used in figures.

\begin{tabular}{|c|c|}
\hline upply Pressure & Rotor Speeds \\
\hline $\begin{array}{l}1-3.08 \text { bar } \\
2-4.46 \text { bar } \\
3-5.84 \text { bar } \\
4-7.22 \text { bar } \\
5-8.25 \text { bar }\end{array}$ & $\begin{array}{l}1-500 \mathrm{cpm} \\
2-1000 \mathrm{cpm} \\
3-2000 \mathrm{cpm} \\
4-3000 \mathrm{cpm} \\
5-4000 \mathrm{cpm} \\
6-5000 \mathrm{cpm} \\
7-6000 \mathrm{cpm} \\
8-7000 \mathrm{cpm}\end{array}$ \\
\hline
\end{tabular}

\author{
Inlet Tangential \\ Velocities \\ 1-High velocity \\ against rotation \\ 2-Low velocity \\ against rotation \\ 3-Zero tangent1al \\ velocity \\ 4-Low velocity \\ with rotation \\ 5-High velocity \\ with rotation
}

The rotor speeds tested to date at the TAMU facility were comparable to those published by Wachter and Benckert. The surface velocities reached here were about half of those reported by Wachter and Benckert. However, Wachter and Benckert published very little data which combines rotor rotation and inlet fluid prerotation. In this study, all possible combinations of independent variables are given. For discussion purposes, the $3000 \mathrm{cpm}$ rotor speed will be highlighted. The results showed little sensitivity to rotor speed and the 3000 cpm point tended to yield the clearest and most descriptive data. No zero rotor speed tests were run, since rotor rotation was necessary to prevent damage to the thrust bearing during shaking.

The inlet tangential velocities attained were up to 2.0 times those published by Wachter and Benckert. The inlet tangential velocities are given in figures 7 and 8 as a function of pressure ratio for both teeth-on-rotor and teeth-on-stator seals. The figures show that inlet tangential velocity remains fairly constant over the pressure ratios tested. There were five test points for inlet tangential velocity; two positive, two negative, and one at zero. The zero inlet tangential velocity point corresponds to the $x$-axis in the figures 7 and 8 . The negative numbers shown in the figures mean that the inlet tangential velocity was opposed to the direction of rotor rotation. The positive numbers mean that the inlet tangential velocity was in the same 
direction as rotor rotation. The two different magnitudes of inlet tangential velocity, for each direction, correspond to the different inlet gulde vane geometries, as discussed in [9]. The ratio of inlet tangential velocity to rotor surface velocity, ranged from about -13 to about 16 . Although the larger numbers are practicaliy unrealistic, they do give insight into the effects of inlet tangential velocity that would have otherwise gone unnoticed. This is most evident in the plots of direct damping versus inlet tangential velocity.

The effects of the three independent variables; pressure ratio, inlet tangentlal velocity, and rotor speed on the dynamic (rotordynamic coefficlents) results will be reviewed in order.

Dynamic Results

For a clrcular orblt of amplitude $A$, the resultant radial and tangential forces developed by the seal model of equation (2) are 1llustrated in figure 9 and are defined by:

$$
\begin{aligned}
-F_{r} / A & =K+c \omega \\
F_{t} / A & =k-c \omega
\end{aligned}
$$

From a stability standpoint, the destabllizing tangentlal force, $F_{t}$, is of most interest. The destabilizing influence comes from the cross-coupled stiffness, $k$, and the stabilizing influence comes from the direct damping, $c$. The radial force usually has little influence on stablitity, except in rare cases involving multistage "back-to-back" centrifugal compressors with midspan seals where large negative direct stiffness values may reduce the natural frequencies. Since the focus of this study was on stability, the cross-coupled stiffness and direct damping results, which have the most influence, will be presented first. The direct stiffness will follow.

Relative Uncertainty

Before proceeding with the results, a statement must be made concerning the uncertainty present in the experimental results. Using the method described by Holman [8], the uncertainty in the dynamic coefficients can be determined. The uncertainty in the force, excitation frequency, and displacement measurements are $0.89 \mathrm{~N}(0.2 \mathrm{lb}), 0.13 \mathrm{~Hz}$, and $0.0013 \mathrm{~mm}(0.05$ mils), respectively. The resulting calculated uncertainty in the stiffness coefficients is $7 \mathrm{~N} / \mathrm{mm}(40 \mathrm{lb} / \mathrm{in})$ and $0.0875 \mathrm{~N}-\mathrm{s} / \mathrm{mm}(0.5 \mathrm{lb}-\mathrm{s} / \mathrm{in})$ for the damping coefficients. Since the measured cross-coupled damping results were rarely greater than the uncertainty, test results are not provided here for this parameter; however data are available in [9].

\section{Cross-coupled Stiffness Comparison}

Figure 10 shows a comparison of the cross-coupled stiffness versus rotor speed for the inlet tangential velocity set of table 2. The figure shows that the teeth-on-rotor labyrinth develops a larger cross-coupled stiffness than the teeth-on-stator configuration. This figure also shows that cross-coupled stiffness results for the the two seals were insensitive to rotor speed over the range of speeds tested $(500-8000 \mathrm{cpm})$. Figure 11 shows the results for cross-coupled stiffness versus inlet tangential velocity for the two seals for the inlet pressure set of table 2. This figure shows that the teeth-on-rotor seal develops consistently larger cross-coupled stiffness than the teeth-onstator seal for all inlet tangential velocity values tested. Figure 12 shows a 
comparison of the cross-coupled stiffness of the two seals versus pressure ratio at $3000 \mathrm{cpm}$. This figure shows that the cross-coupled stiffness of both seals increase with pressure rat10. However, the cross-coupled stiffness for the teeth-on-stator seal levels off under choked conditions (Pr>5.84 bar).

\section{Direct Damping Comparison}

Figure 13 shows a comparison of the direct damping versus inlet tangential velocity for the inlet pressure set of table 2. The results show that the teeth-on-rotor case also develops larger direct-damping coefficlents than the teeth-on-stator case. This figure also shows that the direct damping for both seals is very sensitive to inlet tangential velocity. Figure 14 shows a comparison of the direct damping versus pressure ratio at $3000 \mathrm{cpm}$. This figure shows that the direct damping for both seals increases with increasing inlet pressure. Figure 15 compares the direct damping versus rotor speed for the inlet pressure set of table 2, and shows that direct damping is relatively insensitive to rotor speed.

Direct Stiffness Comparison

Figure 16 shows the results for direct stiffness versus rotor speed with the inlet pressure set of table 2. The figure shows that the teeth-on-rotor case develops a substantially larger magnitude of direct stiffness than the teeth-on-stator case. Note that the direct stiffness is negative which would reduce the system natural frequency and reduce the stability. Figure 17 shows a comparison of the direct stiffness for the two seals versus pressure ratio at $3000 \mathrm{CPM}$. This figure shows that the magnitude of direct stiffness increases with increasing pressure ratio for both seals. The direct stiffness for the teeth-on-stator seal seems to level of for choked exit conditions ( $\operatorname{Pr}>5.84$ bar). Figure 18 shows a comparison of the direct stiffness versus inlet tangential velocity for the two seals for the inlet pressure set of table 2 . The figure shows that the direct stiffness for the teeth-on-stator seal increases with increasing inlet tangential velocity, while the direct stiffness for the teeth-on-rotor seal decreases with increasing inlet tangential velocity.

\section{Whirl Frequency Ratio Comparison}

Since a direct comparison of the coefficients of the two seals does not show any clear stabllity advantage, another method of comparison must be used. One method in which the dynamic coefficients of the two seals can be directly compared is through their respective non-dimensional whirl frequency ratios. Whirl ratio is defined by

\section{Whirl ratio $=k / C \Omega$}

where $\Omega$ is the shaking frequency, and is the ratio of the destabilizing Influence of the cross-coupled stiffness and the stabilizing influence of direct damping. From a stabllity viewpoint, a minimum whirl ratio is desirable. Figure 19 shows a comparison plot of the whirl frequency ratios for the two seals versus inlet tangential velocity with the inlet pressure set of table 2, and shows that the teeth-on-stator seal has a smaller whirl ratio than the teeth-on-rotor seal for positive inlet tangential velocities. This result is significant because most turbomachines have positive inlet tangential velocities for seals and teeth-on-stator seals are shown to be clearly superior to teeth-on-rotor seals from a stability viewpoint. 
CONCLUSIONS

Test results have been presented for stiffness and damping coefficients of teeth-on-rotor and teeth-on-stator labyrinth seals which are geometrically similar. The seals were tested under identical operating conditions to investigate the influence of rotor speed, pressure ratio and inlet tangential velocity on the rotordynamic coefficients.

The experimental results of the previous section support the following conclusions:

(1) The stiffness and damping coefficients are insensitive to rotor speed for both seal conflgurations tested. This may be due to a lack of shear forces developed by the seals and may change as higher speeds are attained.

(2) The stiffness and damping coefficients are very sensitive to inlet tangential velocity.

(3) The stiffness and damping coefficients increase with increasing inlet pressure.

(4) From a rotordynamic standpoint, the teeth-on-stator seal is more stable than the teeth-on-rotor seal for positive inlet tangential velocity.

As a point of interest, the theory of reference [10] was in reasonable agreement with the cross-coupled stiffness results presented here. However predictions for direct stiffness and damping are unsatisfactory. Details of the comparison are provided in reference [9].

\section{REFERENCES}

1. Childs, D., Nelson, C., Nicks, C., Scharrer, J., Elrod, D., Hale,.K., "Theory Versus Experiment for the Rotordynamic Coefficients of Annular Gas Seals: Part 1, Test Facility and Apparatus," 85-Trib-1, ASME-ASLE Joint Lubrication Conference, Atlanta, GA, 8-10 October 1985; also recommended for ASME Trans. Journal of Tribology Technology.

2. Nelson, C., Childs, D., Nicks, C., Elrod, D., "Theory Versus Experiment for the Rotordynamic Coefficients of Annular Gas Seals: Part 2, Constant-Clearance and Convergent-Tapered Geometry", 85-Trib-2, ASME-ASLE Joint Lubrication Conference, Atlanta, GA, 8-10 October 1985; also recommended for ASME Trans. Journal of Tribology Technology.

3. Wachter, J., and Benckert, H.,"Querkrafte aus Spaltdichtungen-Eine mogliche Ursache fur die Laufunruhe von Turbomaschinen," Atomkernenergie Bd. 32, 1978, Lfg. 4, pp. 239-246.

4. Wachter, J., and Benckert, H., "Flow Induced Spring Coefficients of Labyrinth Seals for Applications in Rotordynamic," NASA CP 2133, Rotordynamic Instability Problems in High Performance Turbomachinery, proceedings of a workshop held at Texas A\&M University 12-14 May 1980, pp 189-212.

5. Benckert, H., "Stromungsbedinte Federkennwerte in Labyrinthdichtungen," Doctoral dissertation at University of Stuttgart, 1980. 
6. Wright, D.V.: Labyrinth Seal Forces on a Whirling Rotor. Rotor Dynamical Instability. Proceedings of the ASME Applied Mechanics, Bioengineering, and Fluids Engineering Conference, June 20-22, 1983, Houston, Texas. pp. 19-31.

7. Brown, R.D, and Leong, Y.M.M.S, "Experimental Investigation of Lateral Forces Induced by Flow Through Model Labyrinth Glands," NASA CP 2338, Rotordynamic Instability Problems in High Performance Turbomachinery, proceedings of a workshop held at Texas A\&M University 28-30 May, 1984. pp. $187-210$.

8. Holman, J.P., Experimental Methods for Engineers, McGraw H1ll, 1978, pp. 45.

9. Scharrer, J., "A Comparison of Experimental and Theoretical Results for Rotordynamic Coefficients for Labyrinth Gas Seals," TRC Report No. SEAL-2-85, Texas A\&M University, May 1985.

10. Childs, D., and Scharrer, J., "An Iwatsubo-Based Solution for Labyrinth Seals-Comparison to Experimental Results," ASME Paper 85-GT-136, ASME Gas Trubine Conference, March 1985, Houston, Texas, also accepted for publication, ASME Trans. Journal of Engineering for Gas Turbine and Power.

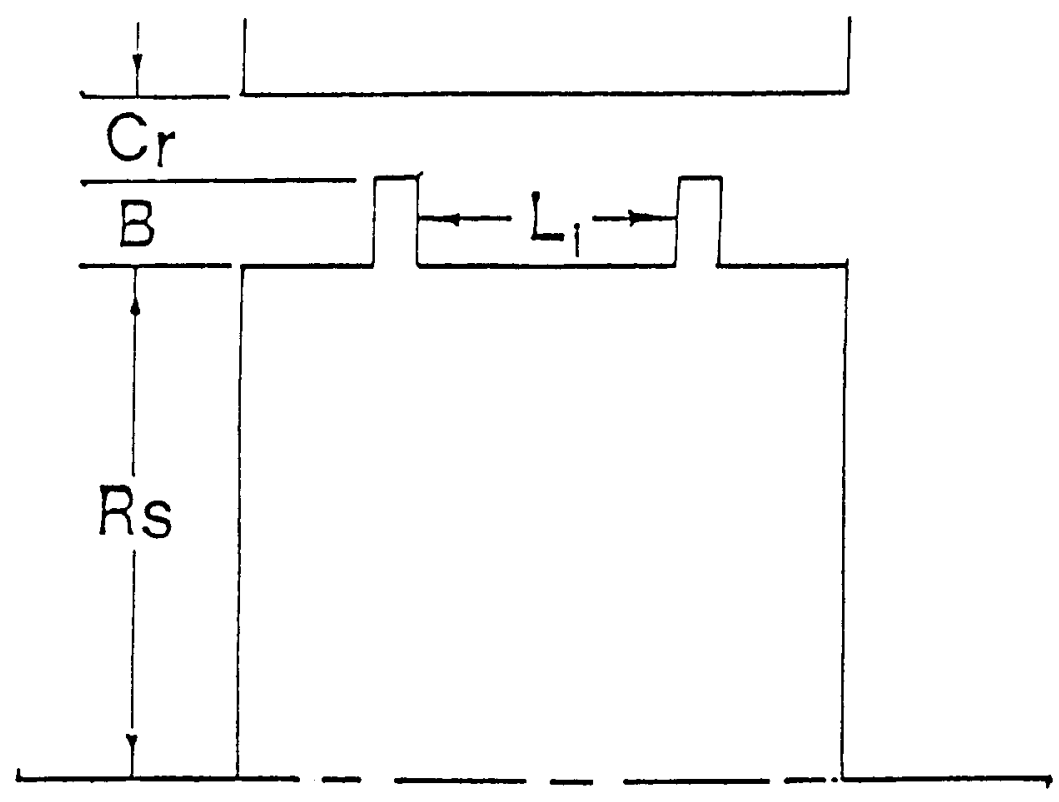

Eig. 1 A typical cavity. 

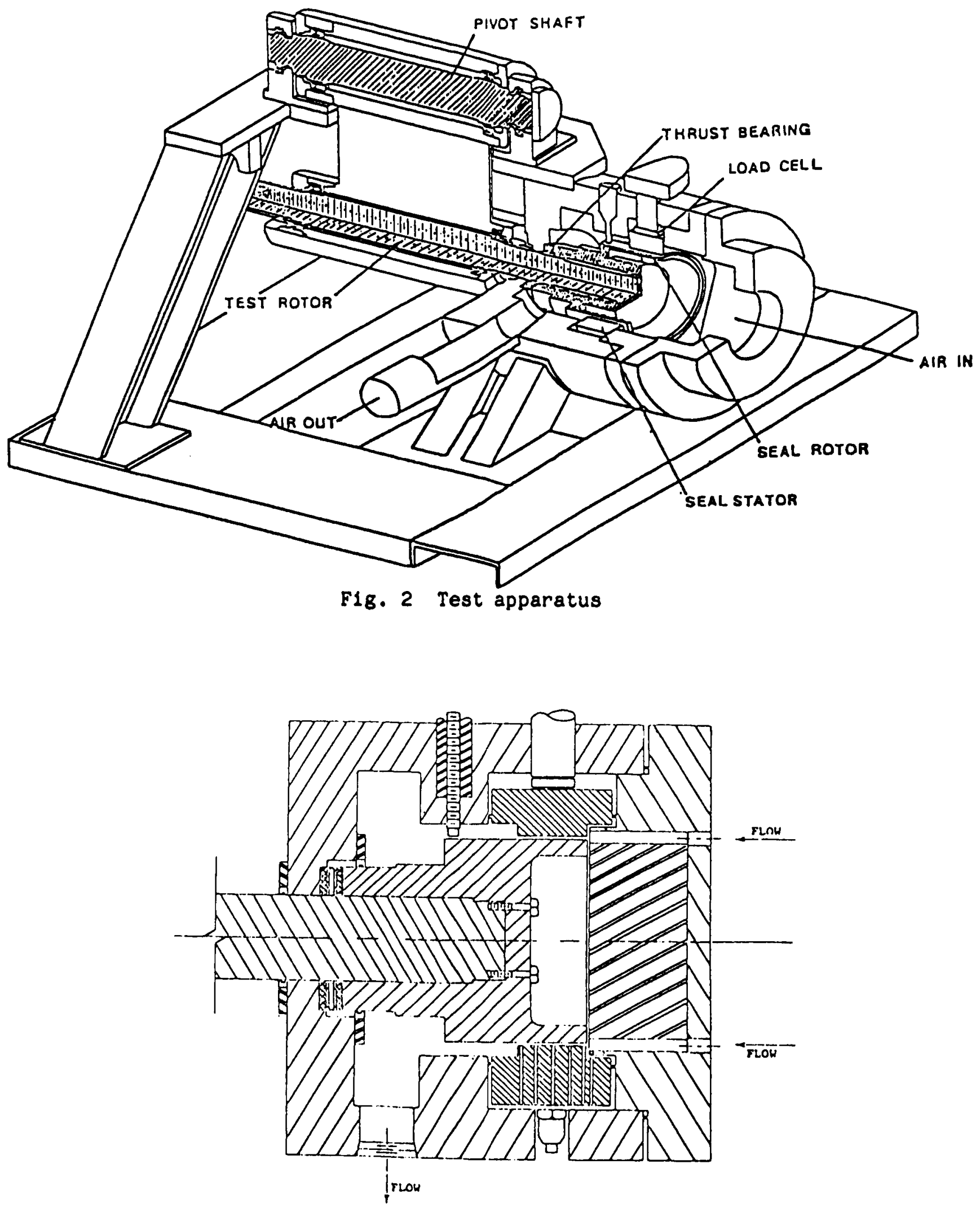

F1g. 3 Cross-sectional view of test section showing smooth stator. 


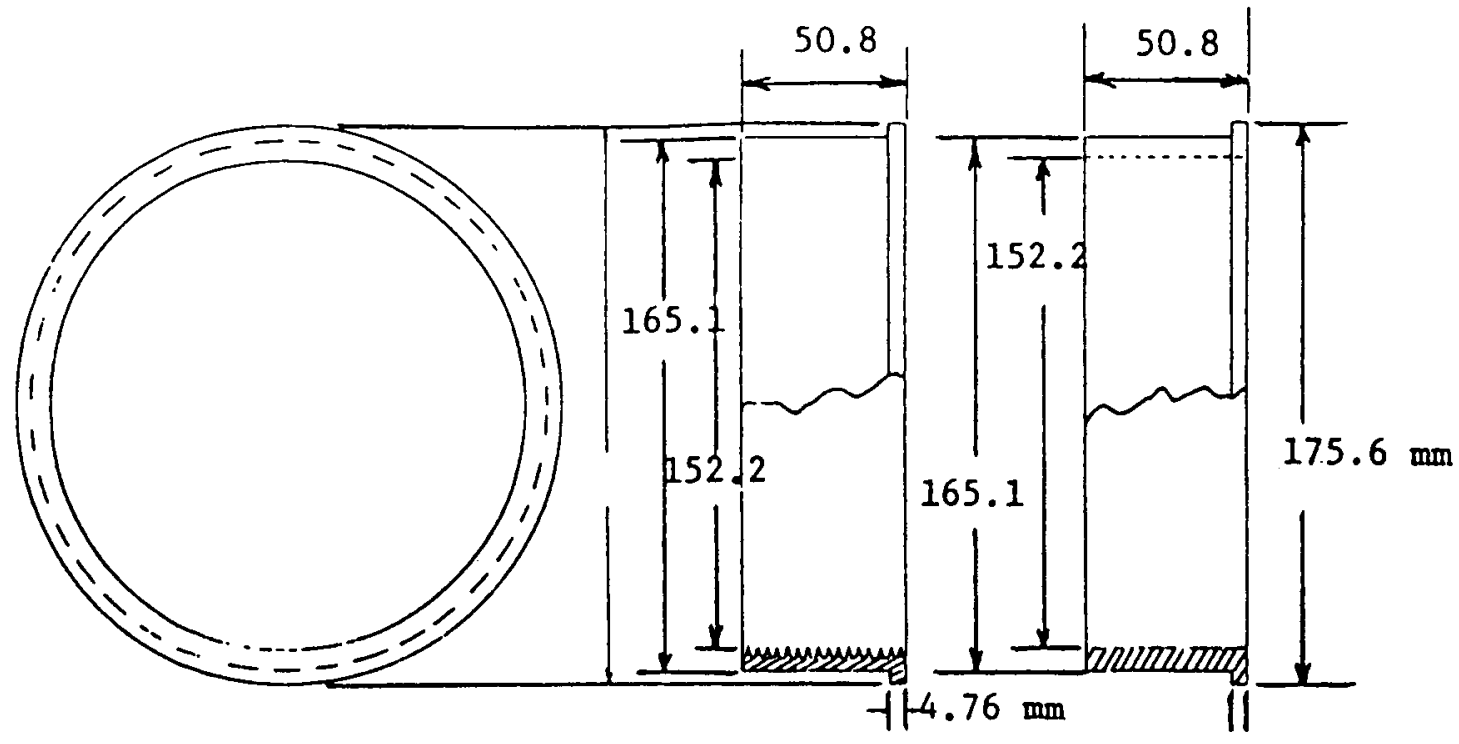

Fig. 4 Detail of smooth and labyrinth stator inserts.

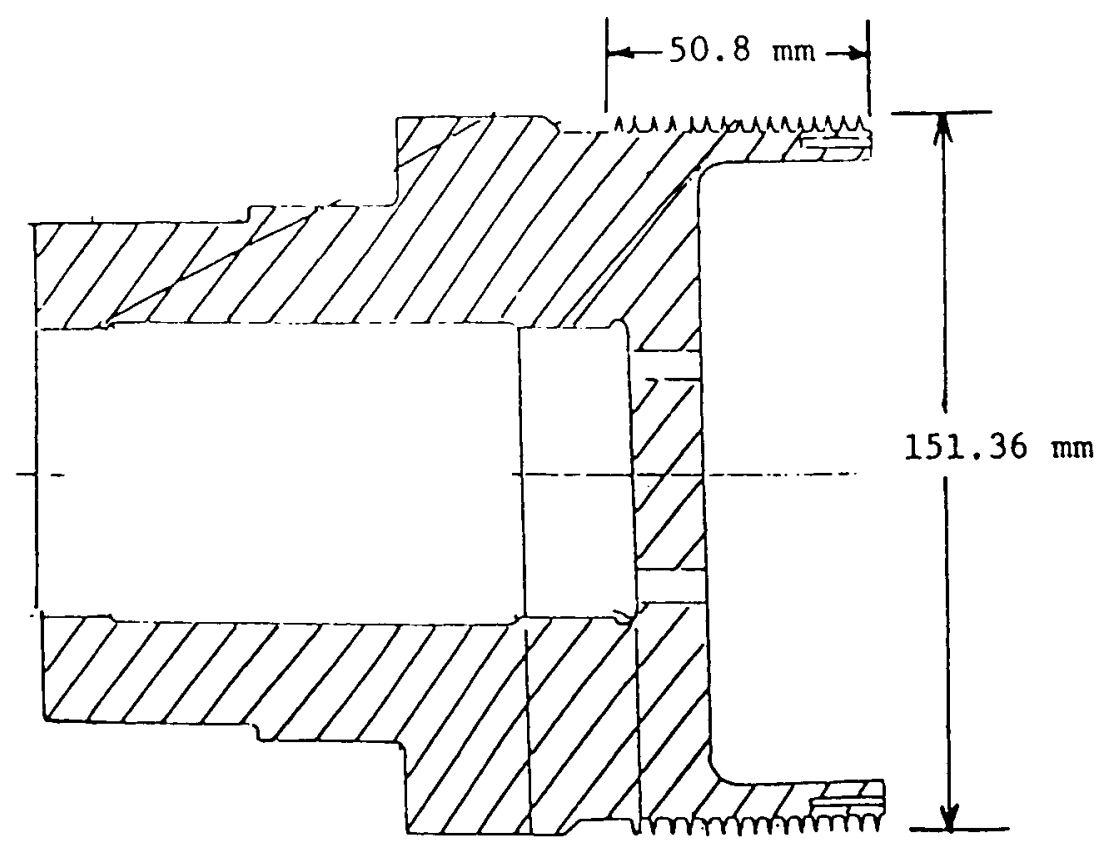

Fig. 5 Cross-section of labyrinth rotor. 


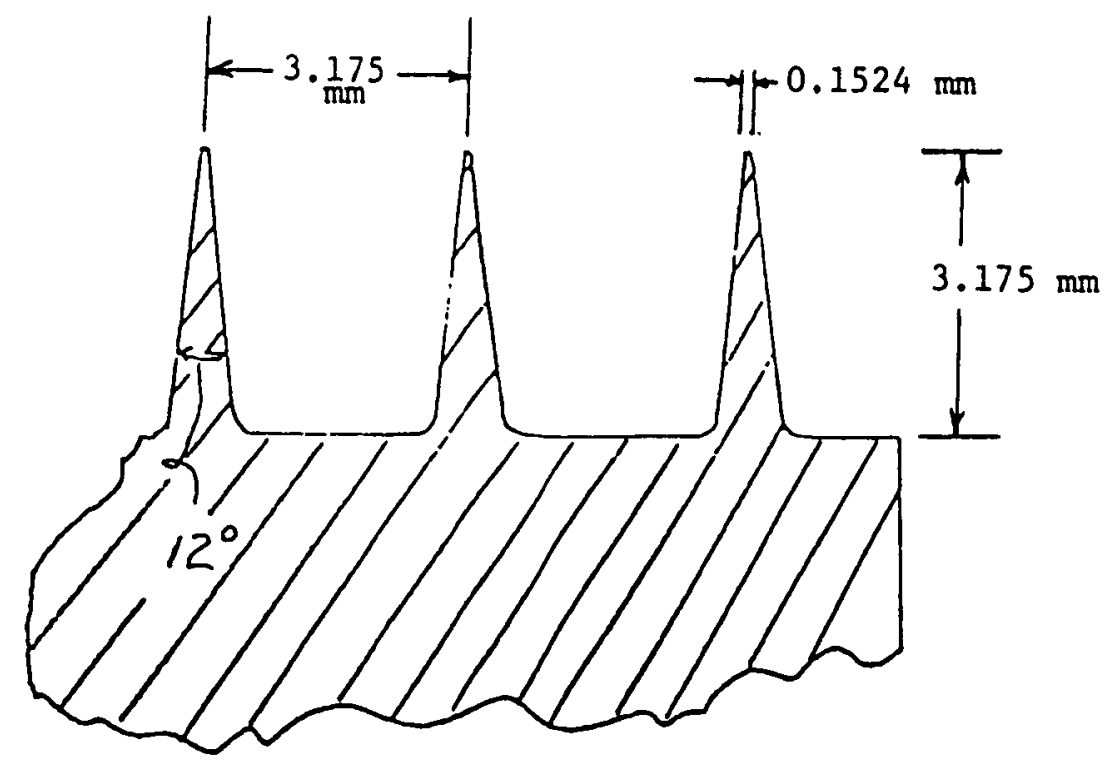

F18. 6 Deta11 of labyrinth teeth for seals tested.

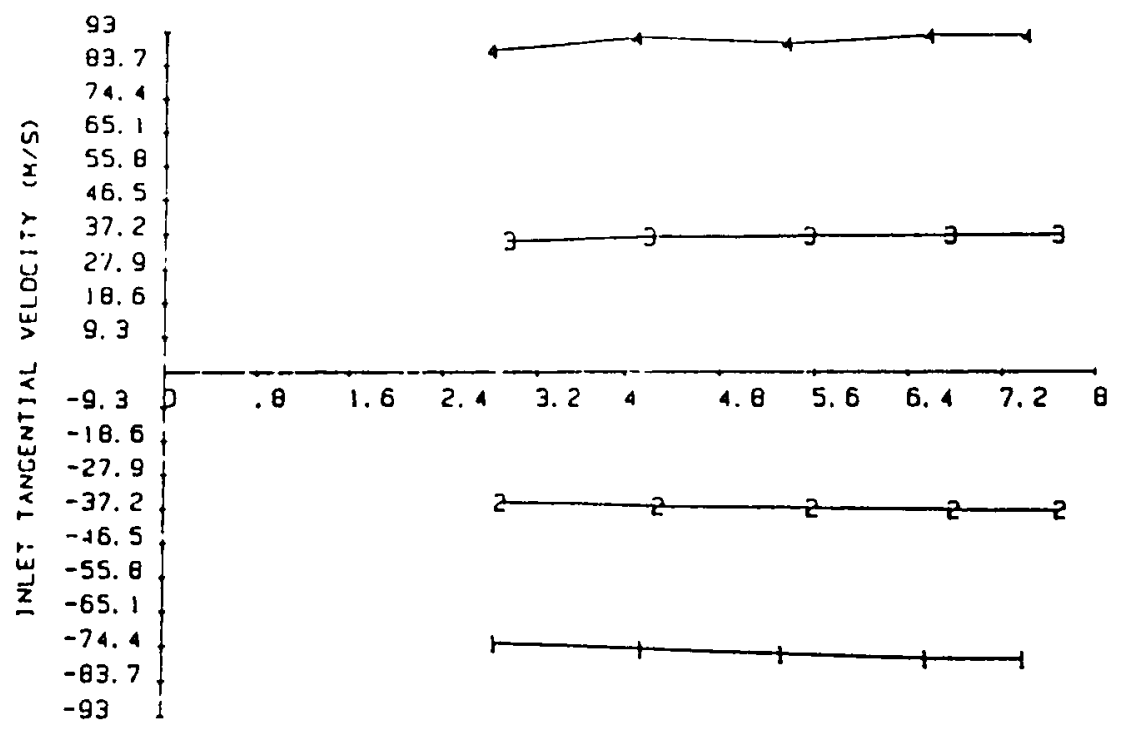

PRESSURE RATIO (BAR/BAR)

Fig. 7 Inlet tangential velocity vs. pressure ratio for teeth-on-rotor labyrinth seal. 


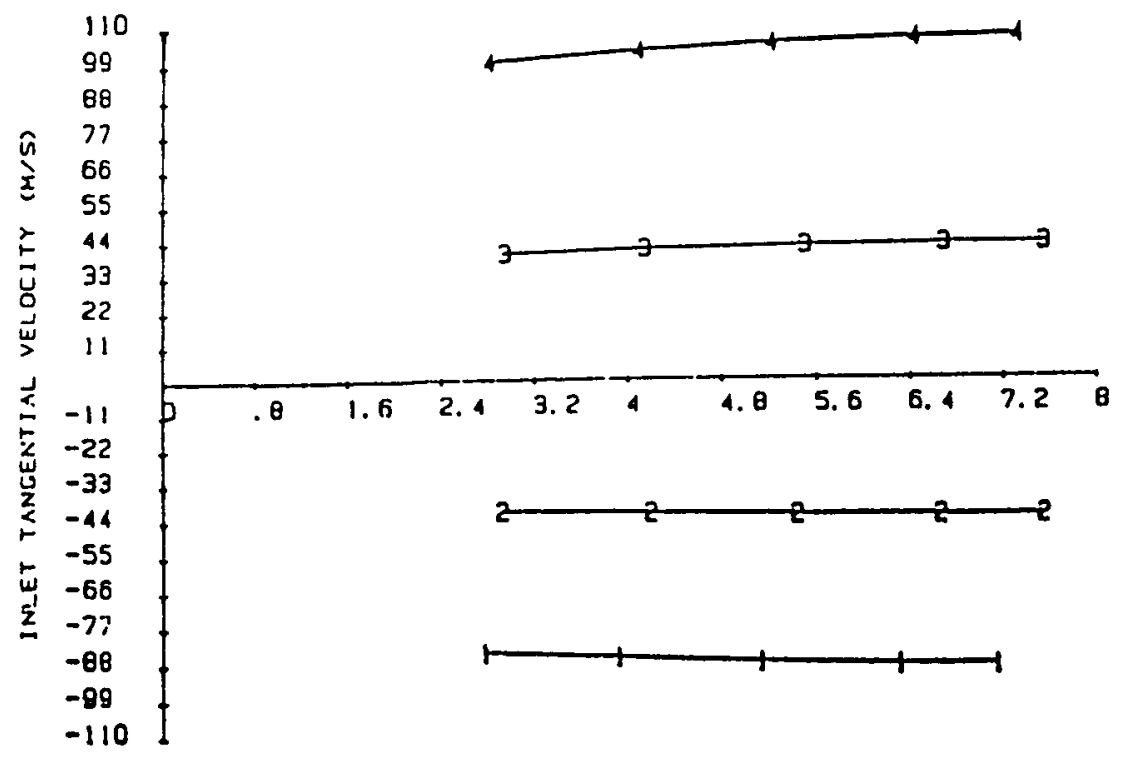

PRESSURE RATIO (BAR/QAR)

F18. 8 Inlet tangentlal velocity vs. pressure ratio for teeth-on-stator labyrinth seal.

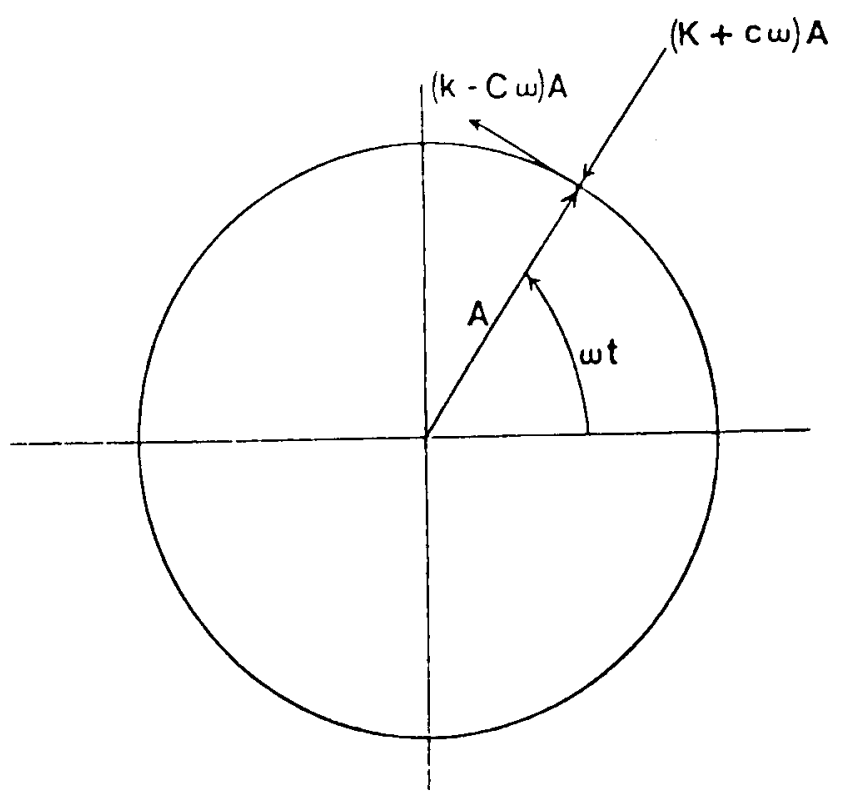

F18. 9 Forces on a rotor. 


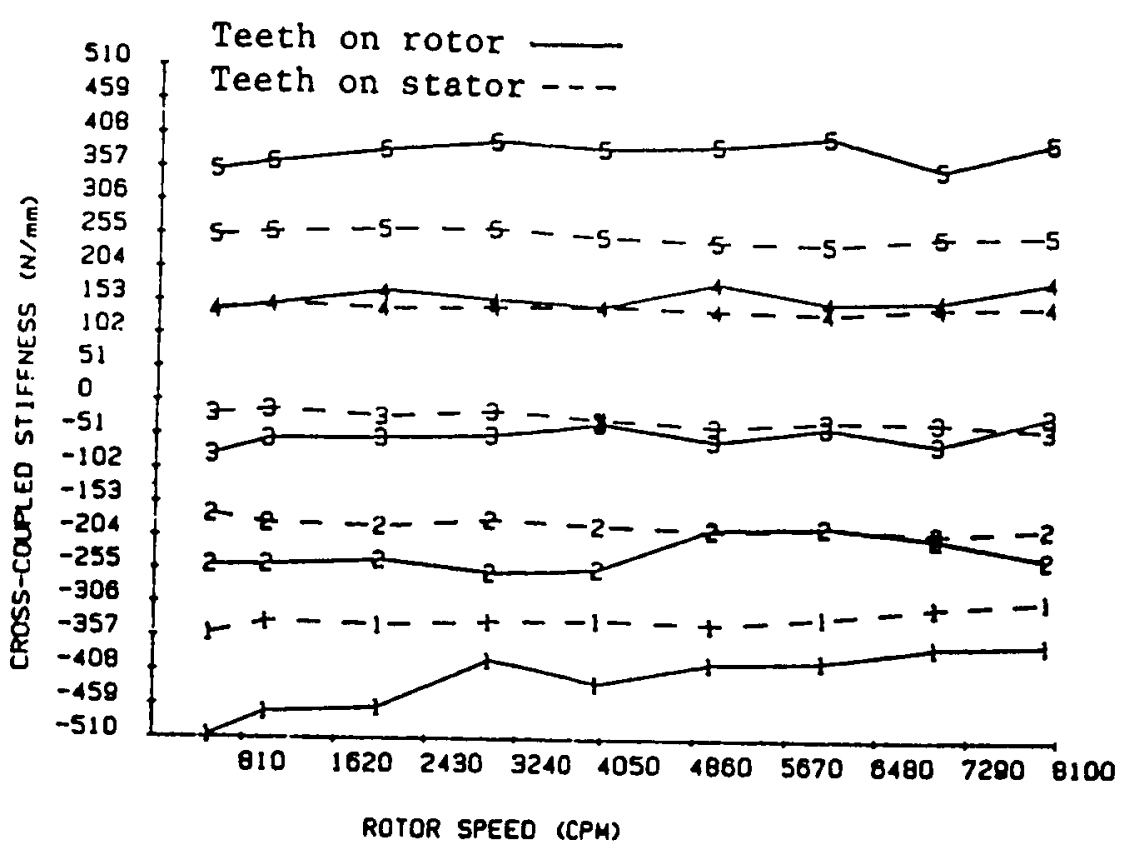

Fig. 10 Cross-coupled stiffness vs. rotor speed.

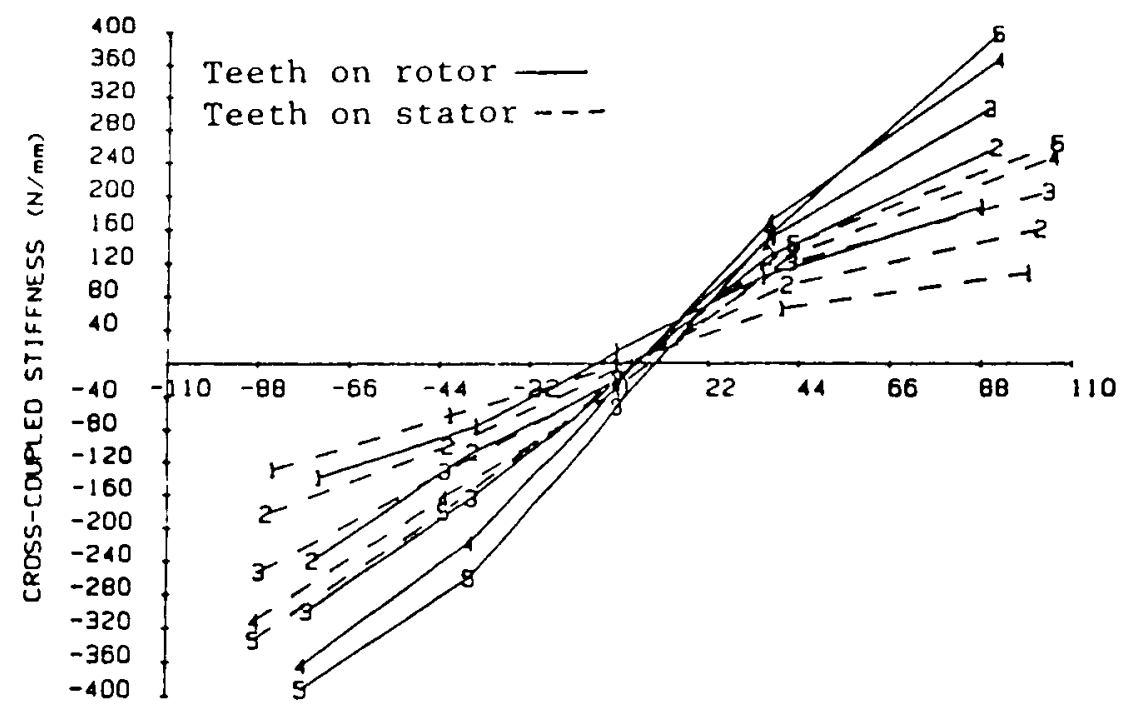

INLET TANCENTIAL VELOCITY (M/S)

Fig. 11 Cross-coupled stiffness vs. Inlet tangential velocity. 


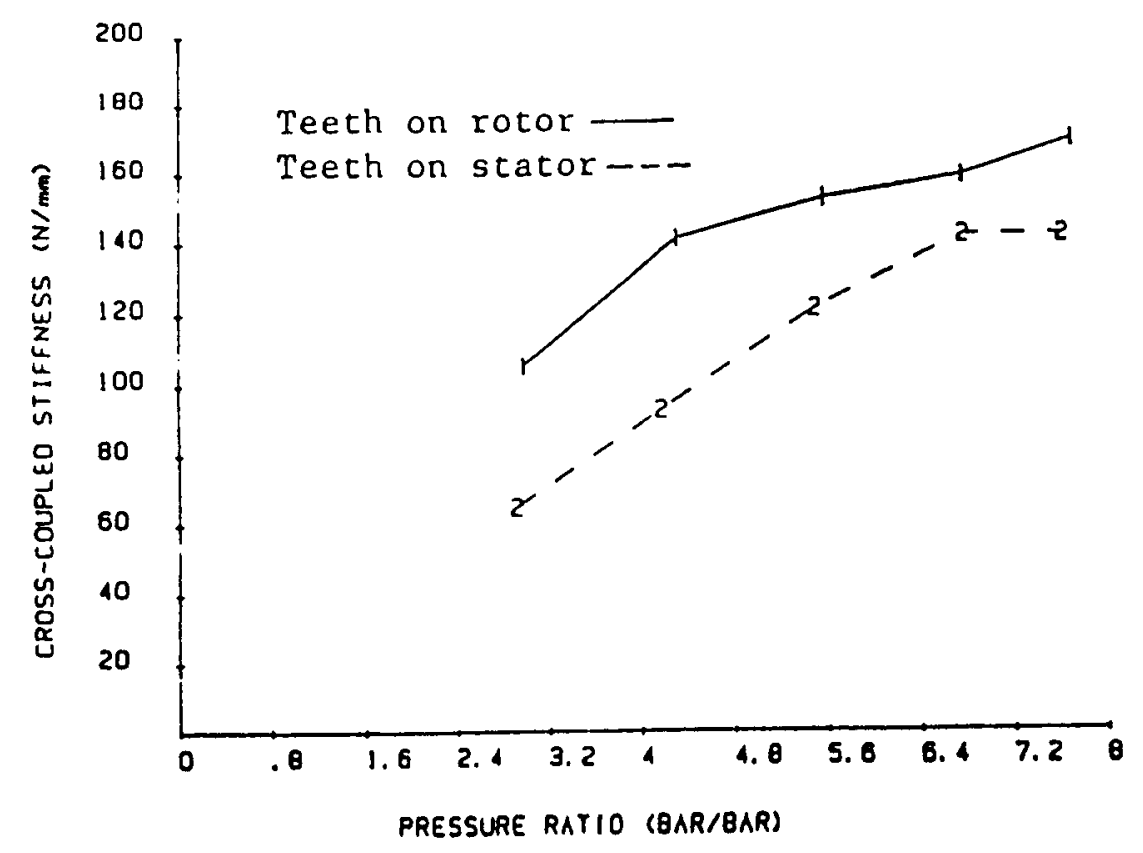

F18. 12 Cross-coupled stiffness vs. pressure ratio.

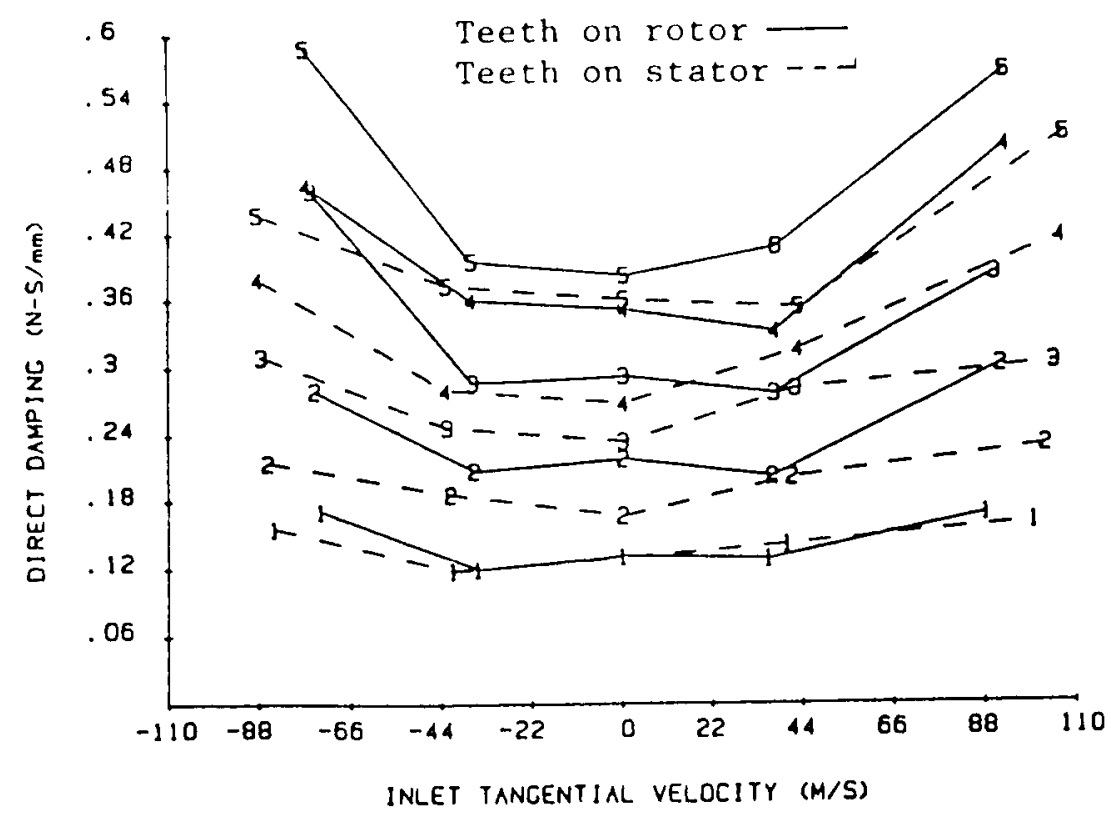

Fig. 13 Direct damping vs. inlet tangential velocity. 


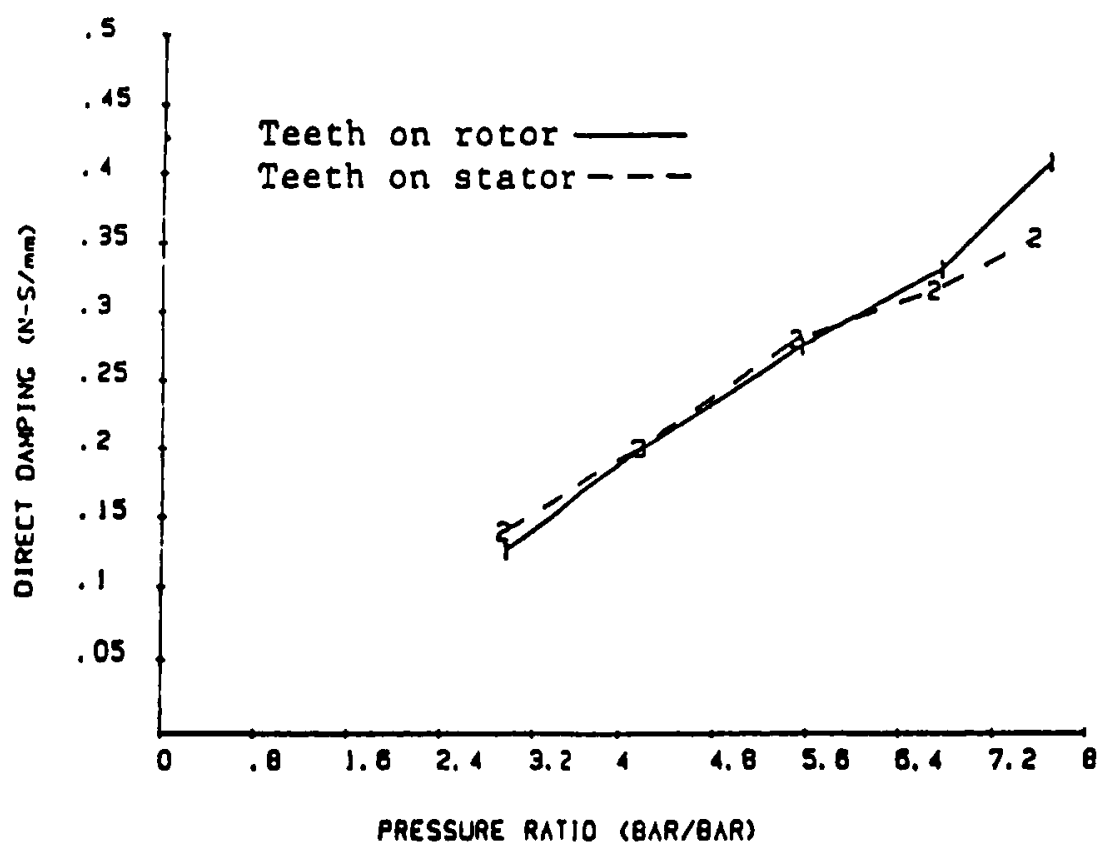

Fig. 14 Direct damping vs. pressure ratio.

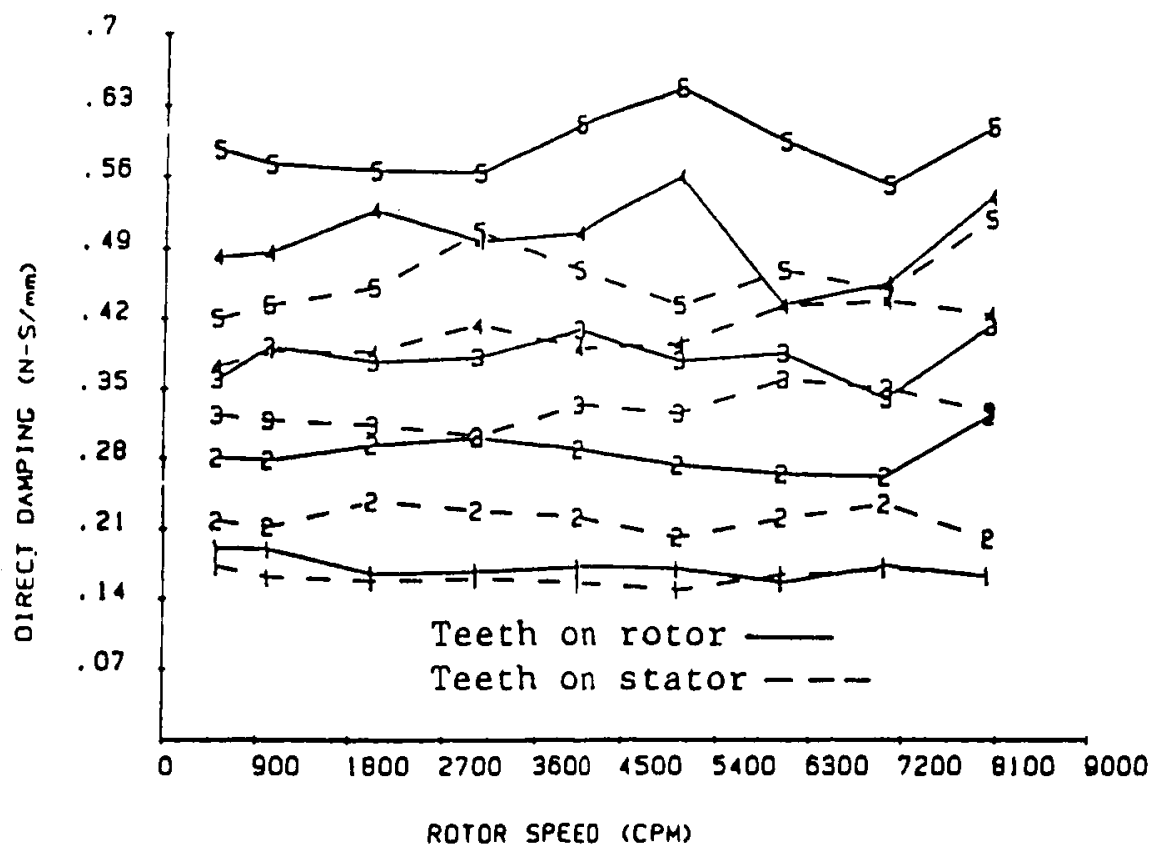

F1g. 15 Direct damping vs, rotor speed. 


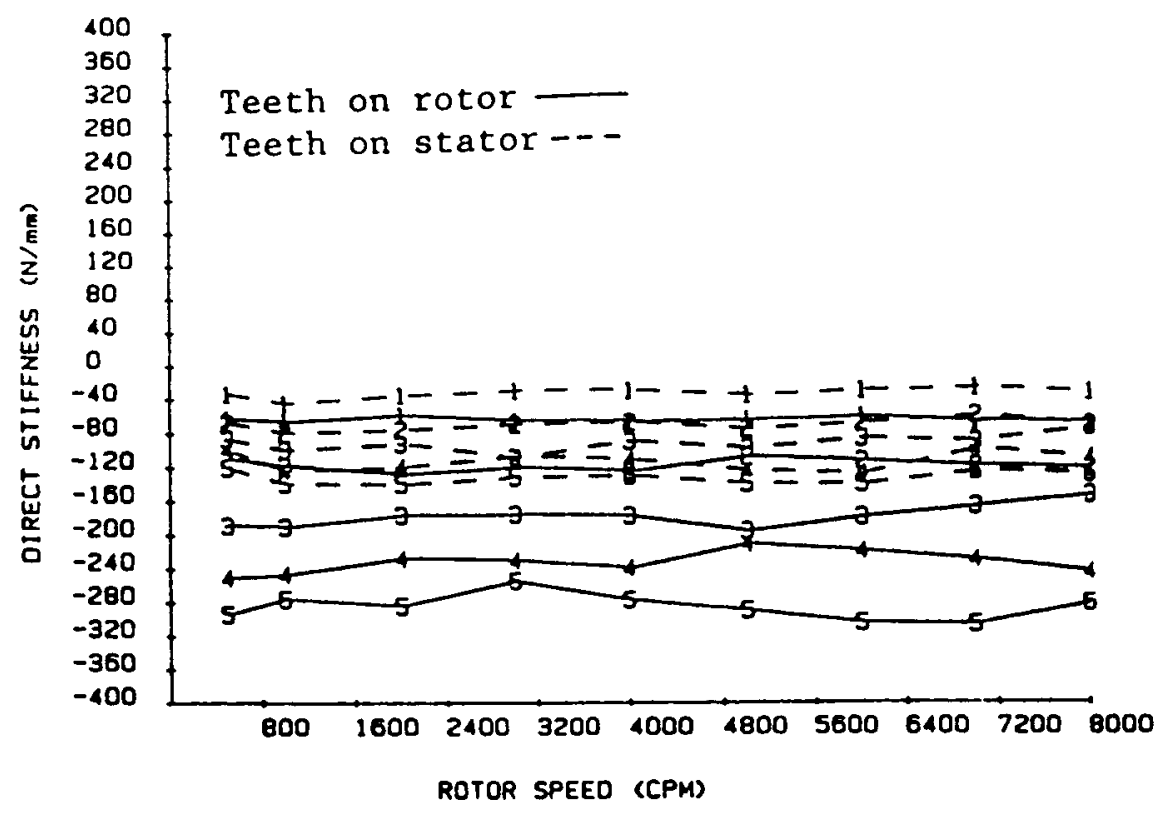

F18. 16 Direct stiffness vs, rotor speed.

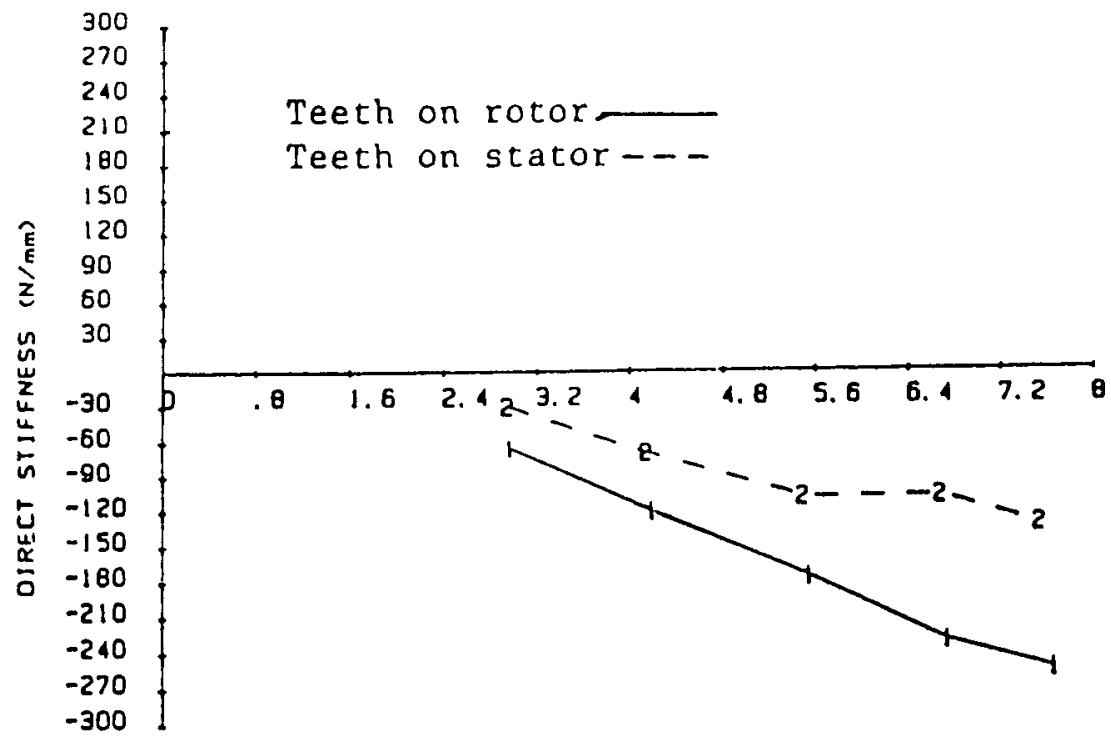

PRESSURE RATIO (BAR/BAR)

Fig. 17 Direct stiffness vs. pressure ratio. 


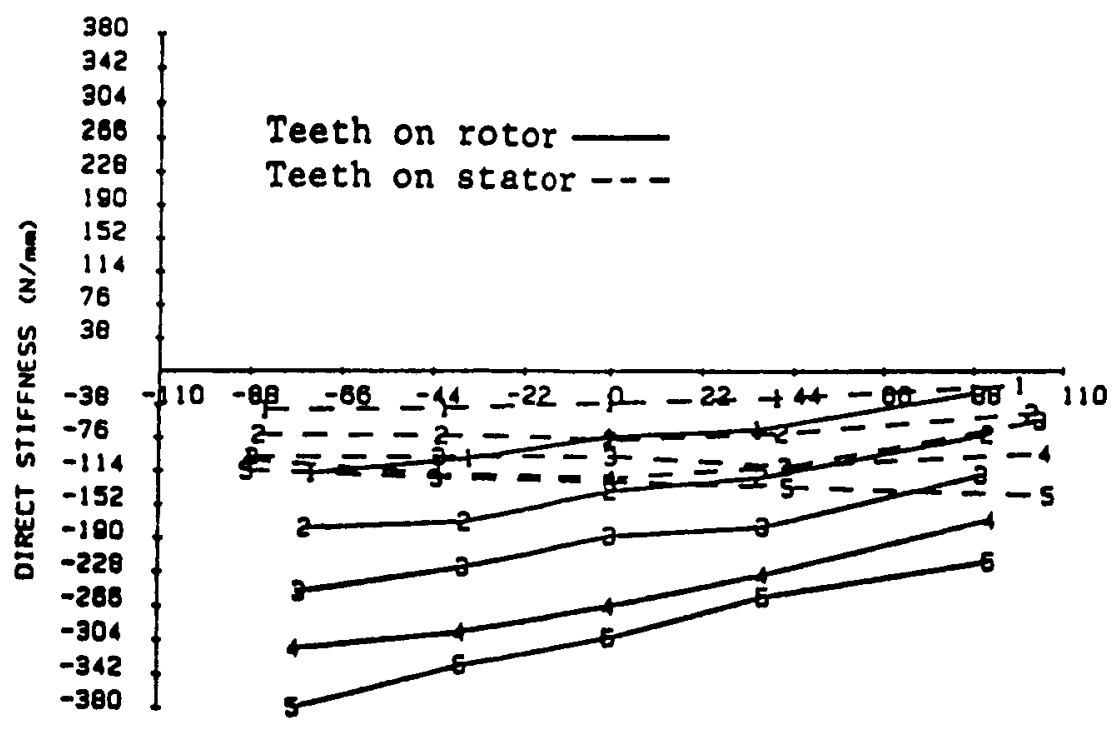

INLET TANGENTIAL VELOCITY (W/S)

F18. 18 D1rect stiffness vs. Inlet tangential velocity.

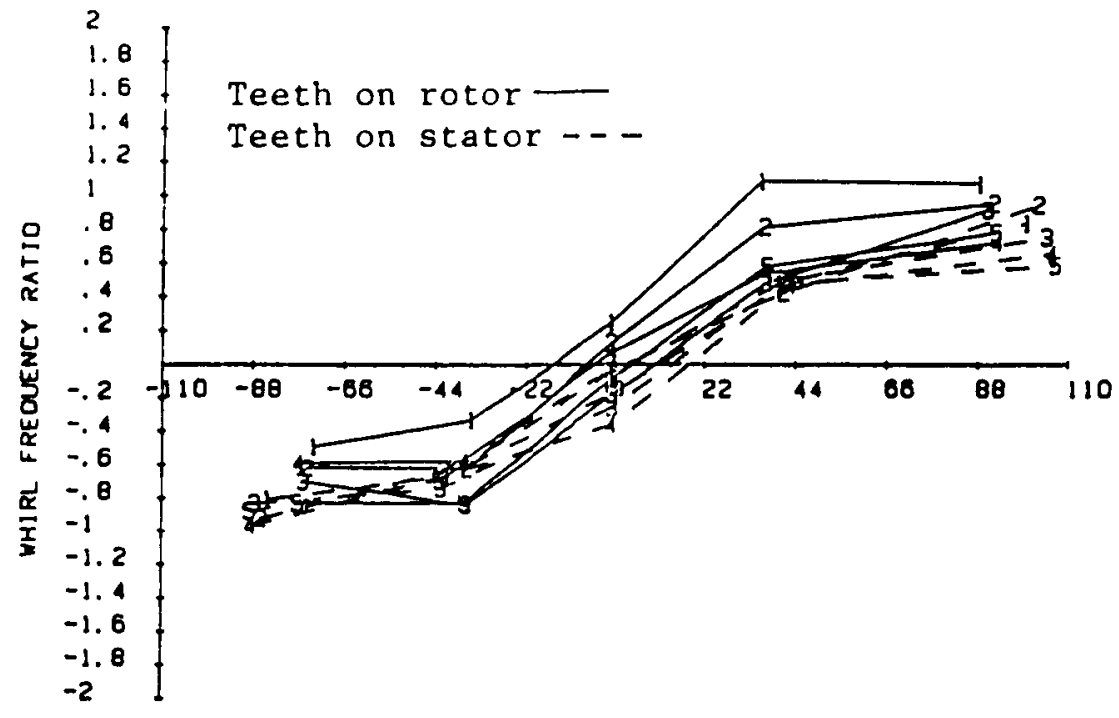

INLET TANGENTIAL VELOCITY (M/S)

F18. 19 Whirl frequency ratio vs. Inlet tangential velocity. 